\title{
A Quantitative Assessment of Japanese Students' Intercultural Competence Developed Through Study Abroad Programs
}

\author{
Shingo Hanada \\ Toyo University, Japan
}

\begin{abstract}
This study explores the factors of study abroad programs that contribute to cultivating intercultural competence. Through an empirically based quantitative examination of 303 Japanese study abroad students, it attempts to gain an understanding of the factors that enhance the development of intercultural competence. Considering that many previous studies worked with students in English-speaking countries, this study examines whether an investigation of Japanese students would yield similar results, given the different context. The primary findings show that program type, prior local language proficiency, and predeparture orientation are predicted to have significant impacts on intercultural competence. The findings clearly demonstrate the importance of empirically based arrangements of study abroad programs based on student and program profiles to enhance students' intercultural competence.
\end{abstract}

Keywords: factor analysis, institutional arrangement, intercultural competence, international education, Japanese students, study abroad programs

The internationalization of higher education has changed higher education modalities. It has had an influence on the promotion of study abroad programs as a dimension of cross-border education. For example, the number of study abroad students has increased, quadrupling from 1.3 million in 1990 to 4.2 million in 2010, and it is expected to increase to 8.0 million by 2025 (Organisation for Economic Co-Operation and Development [OECD], 2016, 2017). As this increase in the number of study abroad students has been seen as a symbol of the internationalization of higher education, different researchers have examined various components of the impact that 
study abroad programs have on students. These components are exemplified by interculturality (Jackson, 2018), cultural resistance (Lemmons, 2015), independence and self-confidence (Walsh \& Walsh, 2018), cultural competency (Hermond, Vairezm, \& Tanner, 2018), awareness of cultural diversity (Wooldridge, Peet, \& Meyer, 2018), intercultural competence (Deardorff, 2009; Yarosha, Lukic, \& Santibáñez-Gruber, 2018), self-efficacy and cultural intelligence (Nguyen, Jefferies, \& Rojas, 2018), contact with host-society (Matera, Imai, \& Pinzic, 2018; Rodriguez \& Chornet-Roses, 2014), cultural adjustment (Basow \& Gaugler, 2017) and acculturation process (Lee \& Negrelli, 2018). This study differs from these existing studies by using a different perspective to focus on the impact of study abroad programs on developing one's intercultural competence. The previous studies have been largely comparative, analyzing and comparing two different kinds of study abroad programs such as short-term and long-term study abroad programs. Moreover, the majority of existing research about study abroad programs explore students who are from English-speaking countries. However, the nature of intercultural competence varies across cultural contexts, and it is therefore important to observe local contexts in intercultural competence research.

It is questionable whether an investigation of Japanese study abroad students would yield similar results given the different context. Although some studies have explored Japanese students (e.g., Hommadova \& Mita, 2016; Martin, Schnickel, \& Maruyama, 2010; Tanaka, 2007), the majority of such studies were largely conducted with qualitative analyses that included students from only one university or study abroad program. Based on the findings of previous research, this study has two aims. First, this study uses a quantitative analysis to explore the impact of study abroad programs on developing intercultural competence among Japanese students. Second, this study extends the existing single-case studies by examining 303 Japanese students at 15 different universities.

\section{Research Question}

This study empirically explores the impact of study abroad programs on cultivating intercultural competence in Japanese students who joined study abroad programs in Canada and the United States. The research question of this study is"Which factors in study abroad programs contribute, either positively or negatively, to the development of students' intercultural competence?" Through an empirically based quantitative examination, this study will attempt to gain a greater understanding of the factors that contribute to the development of intercultural competence. In this study, developing intercultural competence refers to cognitive, affective, and behavioral developments that are related to cultural differences based on Bennett's developmental model of intercultural sensitivity (DMIS) (Bennett, 1993; Hammer, 2011).

\section{Backgrounds of Japanese International Students}

The term "international student," when used in Japanese policy papers, generally refers to both full-time Japanese international students, who study at foreign higher 
education institutions, and Japanese students who participate in study abroad programs that have been mostly arranged by Japanese higher education institutions. Japan has been encouraging an increase in both types of these for Japanese international students. For example, Japan's Revitalization Strategy -Japan is Backwas released by the Japanese government as a current, national fundamental policy to address the necessity of sending more Japanese students abroad. This policy tackles the drastic decrease, from 82,945 in 2004 to 53,197 in 2014 (Ministry of Education, Culture, Sports, Science and Technology, 2017), in the number of Japanese full-time international students who studied at foreign higher education institutions. These figures include both types of Japanese international students. As a possible countermeasure, the policy aims to offer more opportunities for Japanese university students to study abroad in order to increase the number of study abroad students to 120,000 by 2020 (The Prime Minister of Japan and His Cabinet, 2015). In this context, there is no clear distinction between full-time international students and study abroad students (i.e., students from Japanese universities who are studying abroad only for a certain period of time).

There is a different outbound trend if one includes only the number of Japanese international students who are participating in study abroad programs that have been arranged by Japanese higher education institutions. For example, Table 1 indicates that the number of this type of student increased by $211 \%$ from 28,804 to 60,810 between 2010 and 2016. In particular, the number of students participating in Japanese short-term study abroad programs (hereafter referred to as "short-term programs," which refers to programs that are shorter than 1 month in duration), increased by 262\% (the highest increase recorded over the same period; Japan Student Services Organization [JASSO], 2012, 2017). By region, short-term programs in North America (the United States and Canada) were the most popular among Japanese students.

Table 1: The Number of Japanese International Students in Study Abroad Programs (JASSO, 2012, 2014, 2016, 2017)

\begin{tabular}{|l|c|c|c|c|c|c|c|}
\hline Year & $<1 \mathrm{mo}$ & $1-3 \mathrm{mo}$ & $3-6 \mathrm{mo}$ & $\begin{array}{c}6 \mathrm{mo}-1 \\
\mathrm{yr}\end{array}$ & $>1 \mathrm{yr}$ & Unknown & Total \\
\hline 2016 & 35,626 & 5,771 & 8,435 & 9,740 & 1,238 & 0 & 60,810 \\
\hline 2015 & 31,432 & 5,858 & 7,120 & 9,269 & 776 & 0 & 54,455 \\
\hline 2014 & 29,933 & 5,959 & 6,566 & 8,856 & 814 & 4 & 52,132 \\
\hline 2013 & 25,526 & 5,288 & 5,344 & 8,122 & 802 & 0 & 45,082 \\
\hline 2012 & 24,220 & 5,333 & 5,233 & 7,510 & 712 & 1 & 43,009 \\
\hline 2011 & 19,374 & 4,883 & 4,802 & 7,087 & 510 & 0 & 36,656 \\
\hline 2010 & 13,626 & 3,996 & 4,468 & 5,412 & 1,302 & 0 & 28,804 \\
\hline $2016 / 2010$ & $262 \%$ & $144 \%$ & $189 \%$ & $180 \%$ & $95 \%$ & - & $211 \%$ \\
\hline
\end{tabular}

Based on the government's policy regarding Japanese international students, this study covers Japanese international students who satisfy two points - program mode and duration. Program mode refers to the content of the study abroad programs, such as study tours, noncredit foreign language education, and study abroad programs for academic credit. The present study concerns programs in which Japanese 
undergraduate students physically travel abroad to participate in education at foreign institutions for a certain period of time. For example, this research includes academic credit programs provided by partnerships between students' home and foreign host universities, in which students participate in regular, full-time curricular programs at a foreign host university. This study also includes English language programs hosted during summer or spring vacations. By contrast, this study does not include Japanese students who are enrolled full time in foreign universities. Furthermore, programs that are hosted at international branch campuses in home countries, which operate under the name of foreign universities, are not recognized as study abroad programs.

Duration refers to the length of study abroad programs. The present study includes study abroad programs that have been arranged by Japanese universities that are as long as 1 year in duration. As shown in Table 1, the short-term program is very popular among Japanese students. By contrast, the long-term program is defined as a program that lasts between 1 month and 1 year in duration.

Given this background and the lack of relevant empirical research that employs this specific classification of international students to focus on developing intercultural competence in Japanese study abroad programs, there is a need to explore the impact of study abroad programs on cultivating intercultural competence as it relates to Japanese students.

\section{Hypothesis}

The hypothesis guiding this study is that the degree of development of intercultural competence through study abroad programs depends on both student profiles and program profiles as variables during students' study abroad. This study uses three student profiles and five program profiles, as shown in Table 2, and seeks the significant variables that are related to the development of intercultural competence. Prior local language proficiency refers to one's proficiency in the official languages of the destination country (i.e., English in this study) before studying abroad. Prior international experience determines whether or not any previous international experience that occurred before studying abroad influences one's degree of intercultural development. Program type refers to whether students participated in academic credit programs or language and culture programs. Predeparture orientation encompasses lectures and workshops offered to students to teach basic theories and concepts of intercultural understanding as well as the destination countries' cultures, before students study abroad.

\section{Table 2: Student Profiles and Program Profiles}

\begin{tabular}{ll}
\hline & \multicolumn{1}{c}{ Variable classification } \\
\hline Student profile & $0-$ Male \\
Gender & $1-$ Female \\
& $0-$ No experience \\
Prior international experience & $1-$ Up to 21days \\
& $2-22$ days or more \\
& $0-$ No score
\end{tabular}




\begin{tabular}{|c|c|}
\hline & Variable classification \\
\hline & $\begin{array}{l}1 \text { - TOEIC } 499 \text { or lower } \\
2 \text { - TOEIC } 400-700 \\
3 \text { - TOEIC } 701 \text { or higher }\end{array}$ \\
\hline \multicolumn{2}{|l|}{ Program profile } \\
\hline Program duration & $\begin{array}{l}0 \text { - Long-term ( } 1 \text { mo or more) } \\
1 \text { - Short-term (less than } 1 \mathrm{mo} \text { ) }\end{array}$ \\
\hline Program type & $\begin{array}{l}0 \text { - English language \& culture } \\
1 \text { - Academic-credited }\end{array}$ \\
\hline Stay type & $\begin{array}{l}0-\text { Homestay } \\
1-\text { Dormitory }\end{array}$ \\
\hline Predeparture orientation & $\begin{array}{l}0-\text { Did not take } \\
1-\text { Did take }\end{array}$ \\
\hline Destination & $\begin{array}{l}0-\text { Canada } \\
1-\text { United States }\end{array}$ \\
\hline
\end{tabular}

Note TOEIC $=$ Test of English for International Communication.

Based on this study's hypothesis, Figure 1 displays the study's conceptual framework.

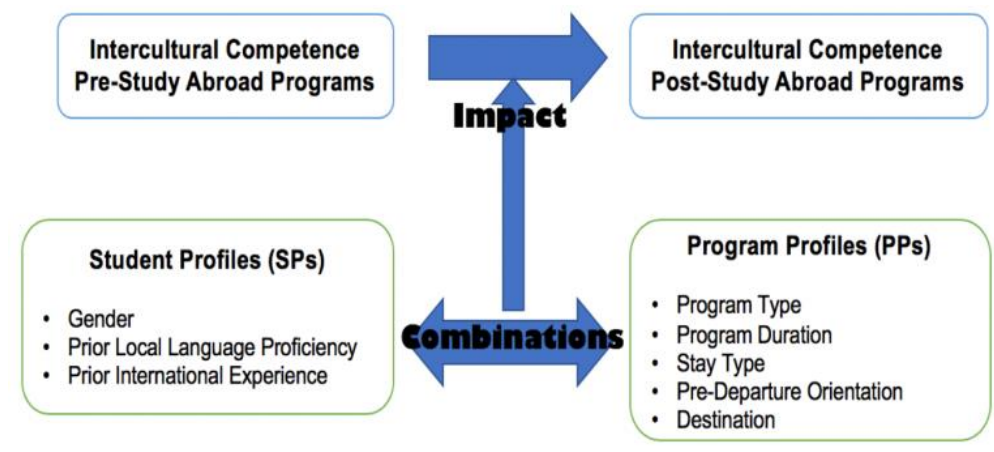

Figure 1: Conceptual Framework

\section{LITERATURE REVIEW}

\section{Intercultural Competence}

Intercultural competence has often been recognized as a capability that supports effective and appropriate interactions with people in different cultural contexts. However, scholars have used varying perspectives to explore the specific components that comprise intercultural competence. For example, Spitzberg and Changnon (2009), in the SAGE Handbook of Intercultural Competence, indicated that scholarly works have advocated for 325 different components of intercultural competence. These components were generally perceived as intercultural competence in one context but not in another. Jackson (2018) mentioned that easy formulas and ready- 
made clichés when examining intercultural encounters and diversity should be avoided. This assertion implies that no particular component of intercultural competence could ever be universally applicable. Therefore, the conceptualization of intercultural competence is highly diverse in terms of different disciplines, terminologies, and scholarly/practical objectives.

Despite the fact that no authoritative definition of intercultural competence prevails in the relevant literature, intercultural competence includes at least three elements: cognitive, affective, and behavioral (Bennett, 2011; Deardorff, 2009; Griffith, Wolfeld, Armon, Rios, \& Liu, 2016; Hammer, 2015). According to Bennett (2011), the cognitive element deals with cultural knowledge, cultural self-awareness, and interaction analysis. The affective element relates to how one sees different cultural qualities such as curiosity, motivation, and open-mindedness to adjust to varying circumstances. The behavioral element relates to one's behavior and the skills adopted in intercultural environments. Different researchers have conceptualized intercultural competence based on these three major elements. Bennett himself conceptualized intercultural competence by identifying six orientations that individuals display in their acquisition of intercultural competence. His development model of intercultural sensitivity stated that as one's experience of cultural differences becomes more complex and sophisticated, one's potential in intercultural competence in terms of behavior, knowing others, and empathetic attitudes to others evolves as relations increase. This study used DMIS as a grounded empirical analysis model.

Another example of such conceptualization is research by Spitzberg and Changnon (2009), who proposed their definition of intercultural competence as "the appropriate and effective management of interaction between people, who to some degree or another, represent different or divergent affective, cognitive and behavioral orientations to the world" (p. 7). Deardorff (2009) offered another empirical study that conceptualized intercultural competence. In this research, the author argued that the major components of intercultural competence are shared by intercultural scholars and higher education administrators. She surveyed both intercultural scholars from a variety of disciplines and higher education administrators from across the United States, from community colleges to research universities, to answer questionnaires in order to measure the desired components of intercultural competence. The results showed that knowledge of others and of self, skills of interpreting others' values, beliefs, and behaviors, and relativizing one's self were the most commonly shared competencies among the group.

\section{Study Abroad Programs and Intercultural Competence}

This study included eight independent variables in its empirical analysis. This section reviews the major previous studies, which examined the same variables to identify the impact of study abroad programs on cultivating intercultural competence.

The first variable is program duration, which is perhaps the most popular variable in this field of empirical research. Does program duration influence the degree of intercultural development? Perhaps the most comprehensive and well-known study in this category is the Georgetown Consortium Project, which was conducted by 
Vande Berg, Connor-Litton, and Paige (2009). This study made specific note of the importance of program duration for the development of intercultural competence based on 1,152 American students from 190 universities in the United States. The authors found that the students who participated in 13-18 week programs, equivalent to approximately one semester of study abroad, showed the greatest increase in their intercultural development. This study also examined students who participated in 4 7-week and 8-12-week programs. It showed a negative impact for students in the 47-week program and small intercultural development for those students in the 8-12week program. In order to reinforce intercultural development, the authors proposed a need to intervene with students' intercultural learning abroad, especially for students who participated in shorter duration programs. By contrast, Nguyen et al. (2018) included 79 study abroad participants to examine the impact of a 5-week program in Puerto Rico and the U.S. Virgin Islands regarding the development of self-efficacy and cultural intelligence. They found that participants' self-efficacy and cultural intelligence were higher after studying abroad than before studying abroad for monocultural individuals. As illustrated by the different results obtained by Vande Berg et al. (2009) and Nguyen et al. (2018), if duration is a determining factor of the effectiveness of studying abroad, this topic remains controversial since some studies (e.g., Czerwionka, Artamonova, \& Barnosa, 2015; Gilin \& Young, 2009; Lee \& Negrelli, 2018) have concluded that even short-term programs are effective while some other studies (e.g., Engle \& Engle, 2004; Kehl \& Morris, 2008; Medina-LopezPortillo, 2004) have found the opposite.

Gender is the second most-commonly used variable among scholars and international educators in this field. Do gender differences influence the degree of intercultural development? Nichols (2011) revealed that gender differences have an impact on the development of intercultural competence in study abroad programs. She concluded that women were more likely to take intercultural and targeted language courses. Furthermore, she found that women were more active in meeting frequently with mentors to discuss cultural adjustment. Vande Berg et al. (2009) also found that females experienced more changes relating to intercultural learning and cultural awareness through studying abroad, while Pedersen (2010) and Williams (2005) did not find a significant difference between male and female students.

How smoothly students can adjust to foreign cultures may be influenced by whether or not they attended predeparture orientations at their home universities. Jackson and Oguro (2018) mentioned that international educators can no longer optimistically expect that study abroad students will develop intercultural sensitivity and become more global-minded people simply by studying abroad. Rather, a professional intercultural intervention is essential to bolster their intercultural learning. This study indicated that many study abroad programs still lack predeparture orientations, or instead, only offer short, nonacademic logistics orientations such as security issues and travel arrangements. Pedersen's (2010) was another study that emphasized the importance of intercultural professional mentoring for students' intercultural competence development. This study examined two groups of students who were studying abroad in a year-long program in England. One group received an intercultural intervention, while the other did not. The students who received the intercultural intervention developed significantly more intercultural competence than 
those who did not. Those who did not receive the intervention showed no statistically significant difference from the control group who had enrolled in study abroad, but had not yet departed (Pedersen, 2010). This result implies that students who receive mentoring from intercultural professionals before leaving their home universities might have smoother entries into the local communities, and they then might have more productive experiences in terms of the development of intercultural competence.

Prior international experiences should be included as a control factor in order to precisely examine the impact of studying abroad between the pre- and poststudy periods. Pedersen (2010) indicated that prior international experiences had a significant impact on intercultural competence while gender, prior language studies, and stay type in the destination country did not. By contrast, Williams (2005) indicated that previous international exposure was not a significant predictive factor influencing a change in intercultural communication skills, including cultural adaptation and sensitivity. Rather, Williams concluded that exposure to different cultures, regardless of whether or not students traveled abroad, was an influential factor in the development of intercultural competence. Exposure to different cultures included having close friends from another culture, previous experiences with traveling or living abroad, attending religious services outside of one's own religion, taking intercultural courses, learning a foreign language, or attending intercultural exhibitions. Vande Berg et al. (2009) indicated that students who had never lived amidst a different culture started out with the lowest level of intercultural competence but showed the greatest development. However, this study concluded that there was no statistically significant relationship between students who have lived among different cultures and those who have not.

Prior local language proficiency is also an important factor in the relationship between foreign language proficiency and intercultural competence. Allen and Herron (2003) followed 25 undergraduate students who had joined a 6-week study abroad program to France. With the use of a quasi-experimental study with a control group of non-study abroad students, they found that the participants significantly improved their French speaking and listening capabilities and experienced a decrease in cultural anxiety. Vande Berg et al. (2009) found that students who had previously studied foreign languages in high school and college had a statistically significant greater development of intercultural competence in comparison to those who had not.

Finally, stay type in destination countries should be included as a potential factor for Japanese students in developing intercultural competence. It is often heard from returning Japanese students that they spent time with Japanese friends in destination countries. International educators often identify this tendency as a negative aspect of study abroad programs for Japanese students. The impact of stay type could be viewed through the students' type of housing in destination countries, which could be homestays, dormitory stays, or others. Rodriguez and Chornet-Roses (2014) examined the construction of student-host relationships among 42 American students who studied in Luxembourg. Their study revealed that the students expected to interact with their host families like family, but in reality, students lacked opportunities for intercultural communication with their host families because these relationships instead functioned as friendships, guest-host relationships, or tenant- 
landlord relationships. Vande Berg et al. (2009) identified a similar finding. They found that students living with other American students or host-country students showed statistically significant gains in intercultural competence, while those living with a host family or with international students from other countries did not.

These previous studies demonstrate that the impact of the above factors on the development of students' intercultural competence deserves ongoing research. In particular, research has yet to identify how study abroad programs affect Japanese students, the majority of whom grew up in monocultural environments.

\section{METHODS}

\section{Data Collection Procedures}

This study analyzed 303 Japanese students who had joined study abroad programs. These students were recruited from 13 Japanese universities and two Canadian universities where study abroad professors or coordinators agreed to invite their students to participate in the study. The 13 Japanese universities, both national and private universities, were chosen to include diverse university characteristics. Also, university locations included both urban and suburban areas in order to include a wide demographic spectrum of Japanese students. Since many Japanese students were studying abroad in the United States, two Canadian universities were consulted to identify Japanese students currently studying abroad in Canada in order to compare two English-speaking countries. Although the researcher used study abroad agencies to collect data from study abroad participants, this study does not include students affiliated with specific agencies so as to generalize participants' backgrounds as much as possible. The data were collected from 2014 to 2015 . Table 3 illustrates the sample population data.

\section{Table 3: Basic Sample Population}

\begin{tabular}{lccc}
\hline Country & $\begin{array}{c}\text { Long-term study } \\
\text { abroad programs }\end{array}$ & $\begin{array}{c}\text { Short-term study } \\
\text { abroad programs }\end{array}$ & Total \\
\hline Canada & 28 & 114 & 142 \\
United States & 29 & 132 & 161 \\
Total & 57 & 246 & 303 \\
\hline
\end{tabular}

For data collection, the researcher contacted international education professionals at the students' home universities and at the two Canadian universities, inviting students to participate in the study. The international education professionals gave the students a URL to use to take the Intercultural Developmental Inventory (IDI) online. Using this procedure and recognizing ethical considerations, the researcher arranged the survey but did not have face-to-face contact with the participants. Thus, the students were able to decide if they wanted to take the IDI without any pressure from the researcher. As a benefit of participation, the students were able to take the IDI for free, and they received individual feedback sheets from the IDI that explained their further development of intercultural competence after studying abroad. 
Based on the collected data, this study then explored the factors that caused changes in intercultural competences through participating in study abroad programs. SPSS (version 25) was used to conduct a multiple regression analysis to determine if there were significant factors in the student and program profiles that were predicted to have significant impacts on a change in intercultural competence between the preand poststudy abroad time periods.

\section{Instrument}

There are various empirical approaches used in intercultural competence research, and each of them focuses on a different element of the research. For example, the psychological approach observes individuals' psychological tendencies, such as stress and shock, in adapting to different cultures. The compositional approach focuses specifically on identifying which individual-level abilities are needed to adapt to different cultures. By contrast, the epistemological approach, which is used in this study, focuses on individuals' cognitive, affective, and behavioral developmental processes involved in adapting to different cultures. The DMIS developed by Bennett (1993) models this approach. The DMIS is comprised of three ethnocentric stages (denial, defense, and minimization), followed by three ethnorelative stages (acceptance, adaptation, and integration). Bennett (1993) defined ethnocentrism as "assuming that the worldview of one's culture is central to all reality" (p. 30) and ethnorelativism as the idea that "cultures can only be understood relative to one another and that particular behavior can only be understood within a cultural context" (p. 46).

Based on the DMIS, Hammer developed the IDI in 1996 as an instrument that can be used to assess a person's intercultural competence by indicating their orientation in the DMIS. The IDI is an online, 50-item, theory-based instrument that uses a 5-point Likert-type scale: $1=$ disagree, 2 = disagree somewhat more than agree, $3=$ disagree some and agree some, $4=$ agree somewhat more than disagree, and $5=$ agree. Willy (2017) conducted a reliability analysis of the IDI and the results showed that the overall score exhibited strong internal reliability, with an estimate of 0.84 . The present study used the IDI to measure students' intercultural competence twice- before and after they studied abroad. The IDI clarifies how students' developmental scores (i.e., one's degree of intercultural competence) changed between the pre- and poststudy abroad periods.

According to Fantini (2009), there are 44 instruments that can be used to assess intercultural competence. Among these, the present study's researcher decided that the IDI would be the best tool for this study because the IDI has three major advantages. The first advantage is that the IDI is a theory-based instrument and is used worldwide. According to the Intercultural Development Inventory, LLC (2018), the IDI provides in-depth insights into how individuals make sense of cultural differences in terms of their mindsets, and it also identifies how individuals respond to cultural differences in terms of skillset (which is defined along a development continuum).

The second advantage is that the IDI has been proven to have strong validity as an instrument that measures intercultural competence for diverse cultural groups, 
including Japanese people. To develop its validity, the IDI has been continuously conducting pilot studies and has developed three revised versions since it was first developed in 1998 (Hammer, 2011). The latest and third version was developed in 2010. The 50 items used in the second version were reviewed by administrating them to 4,763 respondents from 11 distinct cross-cultural groups, including 277 Japanese respondents (Hammer, 2011). These respondents were deliberately chosen from both high schools and universities and from for-profit and non-profit sectors to have diverse respondents. In order to avoid problems arising from the influence of language proficiency in assessing intercultural competence, the IDI developed a rigorously back-translated Japanese version, which enabled Japanese participants to complete the IDI in their native language. This development was a very important step for the present study, as a certain number of this study's participants were students studying abroad for the first time and they did not have sufficient English proficiency to answer IDI questions in English. The IDI, therefore, can be viewed as a cross-culturally valid instrument that can be used to measure intercultural competence.

The third advantage of the IDI is that it is a very sophisticated psychometric measuring instrument. In analyzing IDI results, a crucial factor in this study's credibility relates to what extent participants answered the questions in a straightforward manner. For example, it might be a risk for this study if some participants intentionally chose answers just because they wanted to obtain high scores. Regarding this point, the IDI's 50 psychometric questions are deliberately created to judge both respondents' perceived orientation score, which represents where the individual or group perceives themselves to be on this developmental continuum, and the developmental orientation score, which indicates where the IDI places the individual or group along the continuum (i.e., the individual's or group's actual level of intercultural competence; Hammer, 2012). The perceived and developmental scores were confirmed in terms of their reliability at .82 and .83 , respectively (Hammer, 2011). Given the two reliability scores, the IDI can assure insusceptibility against respondents' social desirability effects.

\section{RESULTS AND DISCUSSION}

Based on the collected sample, a multiple linear regression analysis was conducted to predict change in intercultural competence (i.e., developmental score) based on student and program profiles to identify if there were significant predictors that contributed to the change. A stepwise selection was applied, which chooses variables that improve the regression model one at a time and repeats this process until no further model improvement is possible. Using the stepwise selection process, gender, program duration, stay type, destination, and prior international experience were all dropped from the selection. By contrast, predeparture orientation, prior local language proficiency, and program type were predicted to have a certain impact on changes in developmental scores between the pre- and poststudy abroad periods. Tables 4 and 5 display this result.

Among the significant predictors, predeparture orientation was the strongest predictor of positive development score change between the pre- and poststudy 
abroad periods $(p<.000)$. This change demonstrates that attending a predeparture orientation has the strongest impact on developing intercultural competence through study abroad programs. Program Type 1 (i.e., academic-credited programs) has a more significant impact compared to English language and culture programs $(p<$ .014). In comparison to a prior local language proficiency of 0 (i.e., no English language test score or students who were not ready to take an English language test because of low English proficiency), a prior local language proficiency of 3 (i.e., the Test of English for International Communication [TOEIC] 701 or higher) was shown to have a positive significant impact on change in intercultural competence $(p<.033)$.

Table 4: Explanatory Factors of Developing Intercultural Competence $(N=$ 303)

\begin{tabular}{lcc}
\hline & $M$ & $S D$ \\
\hline Pretest average of development score - posttest average & 2.3447 & 11.64340 \\
$\quad$ development score & & \\
Pretest average of development score & 83.5520 & 13.11533 \\
Gender & 0.3729 & 0.48439 \\
Prior International Experience 1 & 0.1848 & 0.38879 \\
Prior International Experience 2 & 0.1056 & 0.30785 \\
Program Type 1 & 0.2211 & 0.41569 \\
Program duration & 0.3696 & 0.48350 \\
Predeparture orientation & 0.0924 & 0.29008 \\
Prior Local Language Proficiency 1 & 0.0891 & 0.28537 \\
Prior Local Language Proficiency 2 & 0.8119 & 0.39145 \\
Prior Local Language Proficiency 3 & 0.3696 & 0.48350 \\
Stay type & 0.5842 & 0.49368 \\
Destination & 0.4686 & 0.49984 \\
\hline
\end{tabular}

Note. *Overall Average of 303 Students: 83.55 (posttest average development score ) $\rightarrow 85.90$ (pretest average of development score ) $(+2.3447)$

\section{Table 5: Regression Model Coefficients}

\begin{tabular}{lccccc}
\hline & $B$ & $S E B$ & $\beta$ & $t$ & $p$ \\
\hline (Constant) & 29.047 & 3.878 & & 7.489 & .000 \\
Pretest average of development & -0.371 & 0.045 & -0.418 & -8.162 & .000 \\
score & & & & & \\
Predeparture orientation & 5.856 & 1.188 & 0.248 & 4.931 & .000 \\
Program Type 1 & 5.432 & 2.194 & 0.133 & 2.476 & .014 \\
Prior Local Language & 4.545 & 2.121 & 0.113 & 2.143 & .033 \\
Proficiency 3 & & & & & \\
\hline
\end{tabular}

Note. $*$ A significant regression equation was found, $F(4,298)=24.608, p<.000$, with an $R_{2}$ of .238. 


\section{Predeparture Orientation}

Among all eight explanatory variables, this study shows that attending predeparture orientations is shown to be the most significant factor in increasing the development of intercultural competence. Table 6 shows that the actual IDI change was 4.66 for students who attended predeparture orientations, and -0.91 for students who did not attend predeparture orientations, while the average change for 303 students was 2.35 . This result clearly shows that predeparture orientations have a significant impact. Also, more students who attended predeparture orientations developed intercultural competence compared to students who did not attend an orientation in both short-and long-term programs. Thus, predeparture orientations are a very effective way to increase the probability that a student will develop intercultural competence regardless of program duration.

\section{Table 6: Impact of Predeparture Orientation by Program Duration}

\begin{tabular}{|c|c|c|c|c|}
\hline & $\begin{array}{l}\text { No Change } \\
\text { (Average IDI } \\
\text { Change) }\end{array}$ & $\begin{array}{l}\text { Positive Change } \\
\text { (Average IDI } \\
\text { Change) }\end{array}$ & $\begin{array}{c}\text { Negative } \\
\text { Change } \\
\text { (Average IDI } \\
\text { Change) }\end{array}$ & Total \\
\hline $\begin{array}{l}\text { Did not take } \\
\text { predeparture } \\
\text { orientation }\end{array}$ & & & & $\begin{array}{c}126 \\
83.19 \rightarrow 82.28 \\
(-0.91)\end{array}$ \\
\hline $\begin{array}{l}\text { Long-term } \\
\text { programs }\end{array}$ & & $\begin{array}{c}17 \\
81.44 \rightarrow 92.24 \\
(+10.80)\end{array}$ & $\begin{array}{c}17 \\
86.21 \rightarrow 73.78 \\
(-12.43)\end{array}$ & 34 \\
\hline $\begin{array}{l}\text { Short-term } \\
\text { programs }\end{array}$ & $\begin{array}{c}1 \\
93.65 \rightarrow 93.65 \\
(0)\end{array}$ & $\begin{array}{c}37 \\
77.04 \rightarrow 86.15 \\
(+9.11)\end{array}$ & $\begin{array}{c}54 \\
86.18 \rightarrow 78.31 \\
(-7.87)\end{array}$ & 92 \\
\hline $\begin{array}{l}\text { Took } \\
\text { predeparture } \\
\text { orientation }\end{array}$ & & & & $\begin{array}{c}177 \\
83.81 \rightarrow 88.47 \\
(+4.66)\end{array}$ \\
\hline $\begin{array}{l}\text { Long-term } \\
\text { programs }\end{array}$ & & $\begin{array}{c}16 \\
85.02 \rightarrow 98.36 \\
(+13.34)\end{array}$ & $\begin{array}{c}7 \\
96.87 \rightarrow 92.85 \\
(-4.02)\end{array}$ & 23 \\
\hline $\begin{array}{l}\text { Short-term } \\
\text { programs }\end{array}$ & & $\begin{array}{c}95 \\
80.42 \rightarrow 91.18 \\
(+10.76)\end{array}$ & $\begin{array}{c}59 \\
87.39 \rightarrow 80.91 \\
(-6.48)\end{array}$ & 154 \\
\hline Total & & & & $\begin{array}{c}303 \\
83.57 \rightarrow 85.88 \\
(+2.31)\end{array}$ \\
\hline
\end{tabular}

Note. IDI = Intercultural Development Inventory.

Furthermore, a more detailed investigation reveals that predeparture orientations are especially helpful for the following two types of students. The first type refers to students who join short-term programs. Among 246 short-term program students, 
only $40 \%$ of students (37 of 92) who did not attend a predeparture orientation developed intercultural competence, while 62\% of students (95 of 154) who did attend an orientation successfully developed intercultural competency skills. Observing the actual IDI change, predeparture orientations contributed to both leveraging positive change and to reducing negative impacts. A primary disadvantage of short-term programs is the limited period of intercultural emersion. The results show that predeparture orientations can compensate for this limitation.

The second type of student are those who had lower pre-study abroad intercultural competence. Table 7 indicates that 22 of $26(85 \%)$ students in the denial group, 50 of $72(70 \%)$ students in the polarization group, and 37 of $73(51 \%)$ students in the minimization group developed intercultural competence. By contrast, the percentage of students who did not attend any predeparture orientation is clearly lower $(77 \%$ in denial, $46 \%$ in polarization, and $30 \%$ in minimization). Likewise, the actual IDI change is persistently higher in students who attended a predeparture orientation than students who did not. Attending a predeparture orientation is strongly recommended given that the majority of students $(n=225)$ were in polarization and minimization groups in the pre-study abroad periods.

\section{Table 7: Impact of Predeparture Orientation by Intercultural Development Inventory (IDI) Orientation}

\begin{tabular}{|c|c|c|c|c|}
\hline & $\begin{array}{l}\text { No Change } \\
\text { (Average IDI } \\
\text { Change) }\end{array}$ & $\begin{array}{c}\text { Positive Change } \\
\text { (Average IDI } \\
\text { Change) }\end{array}$ & $\begin{array}{c}\text { Negative Change } \\
\text { (Average IDI } \\
\text { Change) }\end{array}$ & Total \\
\hline \multicolumn{5}{|l|}{ Denial } \\
\hline $\begin{array}{l}\text { Did not take predeparture } \\
\text { orientation }\end{array}$ & & $\begin{array}{c}10 \\
64.15 \rightarrow 77.30 \\
(+13.15)\end{array}$ & $\begin{array}{c}3 \\
65.81 \rightarrow 58.06 \\
(-7.75)\end{array}$ & 13 \\
\hline Took predeparture orientation & & $\begin{array}{c}22 \\
64.54 \rightarrow 80.06 \\
(+15.52)\end{array}$ & $\begin{array}{c}4 \\
65.52 \rightarrow 61.29 \\
(-4.23)\end{array}$ & 26 \\
\hline \multicolumn{5}{|l|}{ Polarization } \\
\hline $\begin{array}{l}\text { Did not take predeparture } \\
\text { orientation }\end{array}$ & & $\begin{array}{c}30 \\
76.47 \rightarrow 85.14 \\
(+8.67)\end{array}$ & $\begin{array}{c}34 \\
79.00 \rightarrow 71.38 \\
(-7.62)\end{array}$ & 64 \\
\hline Took predeparture orientation & & $\begin{array}{c}50 \\
77.74 \rightarrow 88.35 \\
(+10.61)\end{array}$ & $\begin{array}{c}22 \\
76.76 \rightarrow 72.30 \\
(-4.47)\end{array}$ & 72 \\
\hline \multicolumn{5}{|l|}{ Minimization } \\
\hline $\begin{array}{l}\text { Did not take predeparture } \\
\text { orientation }\end{array}$ & $\begin{array}{c}1 \\
93.65 \rightarrow 93.65 \\
(0)\end{array}$ & $\begin{array}{c}14 \\
94.16 \rightarrow 103.16 \\
(+8.99)\end{array}$ & $\begin{array}{c}31 \\
93.30 \rightarrow 84.56 \\
(-8.73)\end{array}$ & 46 \\
\hline Took predeparture orientation & & $\begin{array}{c}37 \\
93.10 \rightarrow 102.73 \\
(+9.63)\end{array}$ & $\begin{array}{c}36 \\
94.85 \rightarrow 87.73 \\
(-7.12)\end{array}$ & 73 \\
\hline \multicolumn{5}{|l|}{ Acceptance } \\
\hline $\begin{array}{l}\text { Did not take predeparture } \\
\text { orientation }\end{array}$ & & & $\begin{array}{c}3 \\
119.67 \rightarrow 93.22 \\
(-26.46)\end{array}$ & 3 \\
\hline
\end{tabular}




\begin{tabular}{|c|c|c|c|c|}
\hline & $\begin{array}{l}\text { No Change } \\
\text { (Average IDI } \\
\text { Change) }\end{array}$ & $\begin{array}{l}\text { Positive Change } \\
\text { (Average IDI } \\
\text { Change) }\end{array}$ & $\begin{array}{l}\text { Negative Change } \\
\text { (Average IDI } \\
\text { Change) }\end{array}$ & Total \\
\hline Took predeparture orientation & & $\begin{array}{c}2 \\
124.25 \stackrel{1}{\rightarrow} 127.71 \\
(+3.46)\end{array}$ & $\begin{array}{c}4 \\
117.22 \rightarrow 107.44 \\
(-9.78) \\
\end{array}$ & 6 \\
\hline \multicolumn{5}{|l|}{ Adaptation } \\
\hline \multicolumn{5}{|l|}{$\begin{array}{l}\text { Did not take predeparture } \\
\text { orientation }\end{array}$} \\
\hline \multicolumn{5}{|l|}{ Took predeparture orientation } \\
\hline Total & 1 & 164 & 138 & 303 \\
\hline
\end{tabular}

\section{Program Type}

Program type demonstrated that academic credit programs are predicted to be more effective in developing students' intercultural competence than English language and culture programs. This result addresses the importance of the quality of learning in study abroad programs. For example, academic-credited programs cover specialized study areas, which do not necessarily include intercultural topics. Nonetheless, these programs require students to see things from an academic perspective, which might help students to see critical differences between their home cultures and the destination countries' cultures. By contrast, English language and culture programs generally aim to study the English language through intercultural topics. Thus, one possibility is that having deeper, more meaningful intercultural experiences is more important for developing intercultural competence than is learning about various intercultural topics such as foods, clothes and fine arts.

\section{Prior Local Language Proficiency}

Only the highest level of prior local language proficiency was found to be statistically significant compared to the lowest level of prior local language proficiency. This result indicates that the correlation between local language proficiency and intercultural competence exists when students have an advanced level of local language proficiency. In other words, this result suggests that local language proficiency does not necessarily impact the development of intercultural competence.

\section{Implications for International Educators}

By conducting statistical analyses, this study indicated that the impact of studying abroad was not uniform for all students but instead differed depending on the student and program profiles. In other words, simply studying abroad may or may not be beneficial. Based on the results, this section presents three major implications of this study for international educators at higher level educational institutions. 


\section{Intercultural Education and English Language Education}

This study suggests that it is very important for international educators to recognize that students do not necessarily develop intercultural competence just by participating in study abroad programs. Instead, the development of intercultural competence through study abroad programs can be enhanced if the home institutions and universities offer pre-study abroad intercultural instruction.

This study clearly indicates that providing students with a predeparture orientation is extremely important for all student types. However, of the 303 students surveyed for this study, only $58.4 \%(n=177)$ were offered predeparture orientations at their home universities. On the other hand, many of these students were offered English language training programs, such as daily English conversation classes for prospective students joining study abroad programs. On this point, this study revealed that there is no statistically significant correlation between prior local language proficiency and a change in intercultural competence via study abroad programs, unless the student had an advanced local language proficiency (i.e., TOEIC 701 or higher). In this research, only 28 of 303 students had reached this proficiency level, which demonstrates that, for the majority of students, English language education alone is insufficient for developing students' intercultural competence through study abroad programs. It is recommended that intercultural education is provided separately from English language education in order to develop intercultural competence.

\section{Data-Evidenced Arrangement of Study Abroad Programs}

The second implication for international educators is the importance of arranging study abroad programs in a way that is based on empirical evidence. In this study, the degree of intercultural competence development varied by the student and program profiles. This study advises that international educators consider at least three points about the study abroad program arrangement.

First, the most important point in an empirically based program arrangement is to understand the students' pre-existing intercultural competence in the pre-study abroad period. This step is essential for improving the positive impact of study abroad programs. For example, Table 7 showed that the lower a student's pre-study abroad intercultural competence (i.e., the three ethnocentric stages of denial, polarization, and minimization), the more effective predeparture orientation tends to be. This result demonstrates that understanding pre-study abroad intercultural competence can be an effective way to provide a better intercultural intervention to improve the impact of study abroad programs.

The second program arrangement is relevant for students in short-term programs. Because of the limited amount of intercultural exposure due to time constraints, the quality of intercultural immersion experiences is crucial to help students develop their intercultural competence. This study found that arranging predeparture orientations that teach the destination countries' culture and the basic theories/concepts involved in intercultural understanding, is an effective way to enhance the possibility of developing students' international competence. The findings of this study indicate 
that the number of Japanese students joining short-term programs has dramatically increased in recent years; however, the proportion of students attending predeparture orientations remains low. This outcome necessitates the arrangement of a predeparture orientation for those students who join short-term programs.

Third, in arranging study abroad programs, it is important to focus on program quality. Based on the government's initiative, many Japanese universities are aiming to send an increased number of students to overseas universities. Also, numerous Japanese universities are expanding their short-term English language and cultural programs. This study indicated that academic-credited programs are more effective than English language and cultural programs in developing students' intercultural competence. It is recommended to international educators that they offer short-term academic programs. To improve the impact of study abroad programs on developing intercultural competence, it is necessary that international educators focus on both the quantity of study abroad participants as well as the quality of the programs.

\section{Limitations}

This study has two major limitations. First, this study used the IDI to examine changes in students' intercultural competence between pre- and poststudy abroad periods. Considering the aforementioned three advantages of the IDI, the IDI is the most reliable instrument for this study. However, it is true that this study's results should not be overgeneralized but instead should be referred to as an IDI case study. Nonetheless, it is also true that no specific measurement instrument has been developed to examine intercultural competence, either universally or perfectly.

Second, this study chose three student profiles, which represent students' major characteristics and might influence the changes in intercultural competence. However, there might be other factors, such as age, major subject areas, grade point averages, and family backgrounds that might impact intercultural competence. As it is not realistically feasible to define all the possible influencing variables and to control for them, the researcher chose gender, prior international experience, and prior local language proficiency as the major variables related to the study abroad programs.

There is also a need to pay attention to evaluation methods. One implication of this study is that the factors that generate quantitative results should be pursued by a qualitative analysis. For example, although the quantitative analysis revealed by how much students developed their intercultural competence via short-term programs, a quantitative analysis alone is insufficient for gaining a more thorough understanding of the learning process. A possible solution is to use a mixed-method study. A mixedmethod analysis allows for a more complete analysis of the findings, as one method complements the other. Quantitative analyses provide objective data but do not always clearly demonstrate which factors shaped the data. Conversely, the qualitative method facilitates a deeper understanding of empirical results by observing the participants or interviewing them. Researcher bias, however, can occur through observations conducted in qualitative analyses.

This study suggests that a single evaluation approach does not sufficiently aid the understanding of the impact of study abroad programs. It suggests that 
understanding intercultural competence should be deepened both vertically (a panel assessment) and horizontally (the assessment channels). It is insufficient to evaluate only the pre- and poststudy abroad periods. A variety of perspectives obtained from professors, international educators, administrators, and study abroad coordinators would be desirable. Assessments by only the students and study abroad coordinators might limit the possibility of accurately capturing students' performance.

Based on the above information, it is recommended that international educators consider a study abroad program arrangement based on varying assessment methods. In this study, the evaluators at the Japanese universities who gauged students' intercultural competence were either study abroad coordinators or the professors who had accompanied the students to their destination countries. It might be helpful to gain additional perspectives from related parties, such as other professors, English language instructors, academic tutors, academic administrative staff, other students, support staff, etc.

\section{CONCLUSION}

This study specifically explores the factors of study abroad programs that contribute to cultivating intercultural competence. Through an empirically based quantitative examination of 303 Japanese study abroad students, the findings show that program types, prior local language proficiency, and predeparture orientations are predicted to have significant impact on intercultural competence. The findings also clearly demonstrate that students do not necessarily develop intercultural competence by only participating in study abroad programs. In order to enrich the impact of study abroad programs on intercultural competence, this study addressed the importance of distinguishing between intercultural education and English language education, dataevidenced arrangements of study abroad programs based on student and program profiles, and the necessity of multiple evaluations as implications for international educators.

By contrast, this study did not provide a specific reason as to why some students had negative changes on the development of intercultural competence. A hypothesis that might explain this result is that intercultural competence does not develop linearly; rather, it develops in back-and-forth movements between stress and adaptation. For instance, W-curve theory (Gullahorn \& Gullahorn, 1963), a major cultural adaptation theory, indicates that people have a back-and-forth experience between experiencing difficulty and progress, as they seek to adapt to different cultures. One possibility is that these students experienced honeymoon periods after they arrived in their destination countries and then regressed in the course of a backand-forth adaptation experience. Since there is a trend in Japan for many Japanese students to join short-term programs, it is possible that these students return home before they fluctuate back to adaption in the back-and-forth process. Nonetheless, this does not mean that short-term programs are inappropriate for developing intercultural competence. Rather, this study finds that students in short-term programs should be encouraged to arrange experiences that will enable them to overcome any stresses or difficulties that arise while in an intercultural environment. For example, it might be advantageous to have Japanese students join group work programs that are comprised 
of people from different cultures. In such programs, the Japanese students would experience the challenge of understanding and accepting the different values and thought processes exhibited by group members who come from other cultures. Interacting with people from different cultures and experiencing both obstacles and progress in achieving a common goal might inspire students to reflect on the nature of the difficulties they encountered and overcame. International educators should encourage such deliberate arrangements of study abroad programs to aid students in learning how to acquire intercultural competence via intercultural emersion in a limited time period.

\section{Future Research}

Based on the findings and limitations, this study indicates four major promising areas for future studies. The first is to focus more closely on exactly how students develop intercultural competence through study abroad programs. This study sought to identify the factors that can be predicted to have significant impacts on the development of students' intercultural competence through study abroad programs. However, this study did not fully investigate the question regarding which specific intercultural experiences gained via studying abroad contributed to the development of intercultural competence. In order to conduct these contextual analyses, this study concludes that additional in-depth qualitative research is necessary.

The second area for further research relates to deepening cultural backgrounds. Given that the majority of existing intercultural competence studies have been conducted from a Western perspective, this study is significant in that it focused on Japanese students. However, it is an empirical study of students who dispatched to North America. Going forward, it is necessary that future studies include a wider range of destination countries to enhance the reliability of the data. Including a wide range of destination countries will also help to address important questions, such as whether or not the outcomes would be different for North America and East Asian countries, with which Japan has more cultural similarities.

The third area for future research would be to develop the research methodology. Assessments of intercultural competence would more beneficial than a point-to-point evaluation. In this study's research design, for example, predeparture orientation is understood as preparatory education in the immediate pre-study abroad period. This definition was therefore limited to sessions that were designed to prepare students for studying abroad through classes on intercultural understanding, local culture and customs, English conversation practice, etc. However, the impact of predeparture orientations on pre-study abroad intercultural competence cannot be clearly separated from the impact of what students learned through their home university's curriculum before their orientation. One possible future study might entail a detailed analysis of both predeparture orientation content and an assessment of what students previously learned from their home university's curriculum. Universities need to consider the importance of linking study abroad programs to the broader university curriculum, including predeparture orientations, before sending students abroad (as suggested by this study). Furthermore, the growth curve for intercultural competence bends back and forth, so a more detailed analysis of why this occurs should be conducted via an 
on-site assessment, especially for medium-term study abroad students. Capturing the impact of study abroad programs more precisely would require tracing students' learning and their intercultural competence from the time they first began receiving intercultural education at their home universities.

Finally, a collaboration between international education and other disciplines would be helpful in order to develop an instrument that can be used for Japanese students. One of the significant benefits of collaboration would be to discover possible solutions to any potential problems with using the IDI. That is, it is necessary to develop a made-in-Japan intercultural assessment inventory. Needless to say, developing an instrument to assess the cognitive developmental process of cultural adaptation is beyond the scope of international education coverage. Rather, creating such an assessment needs to be considered from three major perspectivesstatistical, epistemological, and through the lens of international education. The epistemological perspective can be used to create a conceptual model, the statistical perspective can be used to apply the conceptual model as an instrument, and the international education perspective can be used to consider the tool's usability in real education. Exploring the possibility of a multidisciplined collaboration on this topic is a promising area for future studies.

\section{REFERENCES}

Allen, H. W., \& Herron, C. (2003). A mixed-methodology investigation of the linguistic and affective outcomes of summer study abroad. Foreign Language Annals, 36(3), 370-385.

Basow, S. A., \& Gaugler, T. (2017). Predicting adjustment of U.S. college students studying abroad: Beyond the multicultural personality. International Journal of Intercultural Relations, 56, 39-51.

Bennett, J. M. (2011). Developing intercultural competence for international education faculty and staff. 2011 AIEA Conference Workshop, San Francisco, CA. Retrieved November 25, 2018 from http://www.pindex.com/uploads/post_docs/1AnalyticICIInterculturalCompetence(PINDEX-DOC-14711).pdf

Bennett, M. J. (1993). Towards ethnorelativism: A developmental model of intercultural sensitivity. In R. M. Paige (Ed.), Education for the intercultural experience (2nd ed., pp. 21-71). Yarmouth, ME: Intercultural Press.

Deardorff, D. K. (2009). Synthesizing conceptualizations of intercultural competence: A summary and emerging themes. In D. K. Deardorff (Ed.), The SAGE handbook of intercultural competence. Thousand Oaks, CA: SAGE.

Engle, L., \& Engle, J. (2004). Assessing language acquisition and intercultural sensitivity development in relation to study abroad program design. Frontier: The Interdisciplinary Journal of Study Abroad, X, 219-236.

Fantini, A. E. (2009). Assessing intercultural competence. In D. K. Deardorff (Ed.), The SAGE handbook of intercultural competence (pp. 456-476). Thousand Oaks, CA: SAGE.

Gilin, B., \& Young, T. (2009). Educational benefits of international experiential learning in an MSW program. International Social Work, 52(1), 36-47. 
Griffith, R. L., Wolfeld, L., Armon, B. K., Rios, J., \& Liu, O. L. (2016). Assessing intercultural competence in higher education: Existing research and future directions. Research Report ETS RR-16-25. http://dx.doi.org/10.1002/ets2.12112

Gullahorn, J., \& Gullahorn, J. (1963). An extension of the u-curve hypothesis. Journal of Social Issues, 19(3), 33-47.

Hammer, M. R. (2011). Additional cross-cultural validity testing of the Intercultural Development Inventory. International Journal of Intercultural Relations, 35, 474-487.

Hammer, M. R. (2012). A resource guide for effectively using the Intercultural Development Inventory (IDI). Berlin, MD: IDI, LLC.

Hammer, M. R. (2015). The developmental paradigm for intercultural competence research. International Journal of Intercultural Relations, 48, 12-13.

Hermond, D., Vairezm, M. R., Jr., \& Tanner, T. (2018). Enhancing the cultural competency of prospective leaders via a study abroad experience. Administrative Issues Journal: Connecting Education, Practice, and Research, 8(1), 18-27.

Hommadova, A., \& Mita, T. (2016). Academic and social challenges of Japanese students during cultural adjustment to the rural U.S. Journal of International and Advanced Japanese Studies, 8, 241-255.

Intercultural Development Inventory, LLC. (2018). The roadmap to intercultural competence using the IDI. 12 reasons for using the IDI. Retrieved November 25 , 2018 from https://idiinventory.com/publications/12-reasons-for-using-the-idi/

Jackson, J. (2018). Interculturality in international education. New York, NY: Routledge.

Jackson, J., \& Oguro, S. (2018). Enhancing and extending study abroad learning through intercultural interventions. In J. Jackson \& S. Oguro (Eds.), Intercultural interventions in study abroad. (pp.1-17). Oxon, OX: Routledge.

Japan Student Services Organization. (2012). 2010 Report of Japanese students participating in study abroad programs through partnerships and etc. (Heisei 22 nendo kyouteitou ni motoduku nihonjin gakusei kaigairyungaku jyoukyou chousa kekka). Retrieved Novembe 25, 2018 from https://www.jasso.go.jp/about/statistics/intl_student_s/2011/_icsFiles/afieldfil e/2016/01/28/short_term10.pdf

Japan Student Services Organization. (2014). 2012 Report of Japanese students participating in study abroad programs through partnerships and etc. (Heisei 24 nendo kyouteitou ni motoduku nihonjin gakusei kaigairyuugaku jyoukyou chousa kekka). Retrieved November 25, 2018 from https://www.jasso.go.jp/about/statistics/intl_student_s/2013/_icsFiles/afieldfil e/2016/01/28/short_term12.pdf

Japan Student Services Organization. (2016). 2014 Report of Japanese students participating in study abroad programs through partnerships and etc. (Heisei 26 nendo kyouteitou ni motoduku nihonjin gakusei kaigairyungaku jyoukyou chousa kekka). Retrieved November 25, 2018 from https://www.jasso.go.jp/about/statistics/intl_student_s/2015/_icsFiles/afieldfil e/2016/03/25/short_term14.pdf 
Japan Student Services Organization. (2017). 2016 Report of Japanese students participating in study abroad programs through partnerships and etc. (Heisei 28 nendo kyouteitou ni motoduku nihonjin gakusei kaigairyuugaku jyoukyou chousa kekka). Retrieved November 25, 2018 from https://www.jasso.go.jp/about/statistics/intl_student_s/2017/_icsFiles/afieldfil e/2018/12/21/short_term16_181221.pdf

Kehl, K. L., \& Morris, J. (2008). Differences in global-mindedness between shortterm and semester-long study abroad participants at selected private universities. Frontiers: The Interdisciplinary Journal of Study Abroad, XV, 67-79.

Lee, J., \& Negrelli, K. (2018). Cultural identification, acculturation, and academic experience abroad: A case of a joint faculty-led short-term study abroad program. Journal of International Students, 8(2), 1152-1172.

Lemmons, K. (2015). Short-term study abroad: Culture and the path of least resistance. Journal of Geography in Higher Education, 39(4), 543-553.

Martin, R., Schnickel, J., \& Maruyama, Y. (2010). A possible selves analysis: Japanese university students in a study abroad program. Intercultural Communication Studies, XIX(2), 202-216.

Matera, C., Imai, T., \& Pinzic, S. (2018). Do you think like me? Perceived concordance concerning contact and culture maintenance on international students' intentions for contact with the host-society. International Journal of Intercultural Relations, 63, 27-37.

Medina-Lopez-Portillo, A. (2004). Intercultural learning assessment: The link between program duration and the development of intercultural sensitivity. Frontiers: The Interdisciplinary Journal of Study Abroad, X, 179-200.

Ministry of Education, Culture, Sports, Science and Technology (MEXT). (2017). 2016 white paper on education, culture, sports, science and technology. Retrieved November $25, \quad 2018$ from http://www.mext.go.jp/b_menu/hakusho/html/hpab201701/1389013_017.pdf

Nguyen, A, D., Jefferies, J., \& Rojas, B. (2018). Short term, big impact? Changes in self-efficacy and cultural intelligence, and the adjustment of multicultural and monocultural students abroad. International Journal of Intercultural Relations, 66,119-129.

Nichols, K. P. (2011). Fostering intercultural competence through study abroad: A gender-based analysis of individual and program factors influencing development. University of Minnesota Libraries Digital Conservancy. Retrieved November 25, 2018 from http://conservancy.umn.edu/bitstream/handle/11299/119984/?sequence=1

Organisation for Economic Co-Operation and Development. (2016). Science, technology and innovation outlook 2016. Available at https://www.oecd.org/fr/sti/oecd-science-technology-and-innovation-outlook25186167.htm

Organisation for Economic Co-Operation and Development. (2017). Education at a glance 2017. Available at https://www.oecd-ilibrary.org/education/education-ata-glance-2017_eag-2017-en 
Pedersen, P. (2010). Assessing intercultural effectiveness outcomes in a yearlong study abroad program. International Journal of Intercultural Relations, 34(1), 70-80.

The Prime Minister of Japan and His Cabinet. (2015). Japan Revitalization Strategy - Japan is back. Retrieved November 25, 2018 from http://www.kantei.go.jp/jp/singi/keizaisaisei/pdf/saikou_jpn.pdf

Rodriguez, S. R., \& Chornet-Roses, D. (2014). How 'family' is your host family?: An examination of student-host relationships during study abroad. International Journal of Intercultural Relations,39, 164-174.

Spitzberg, B. H., \& Changnon, G. (2009). Conceptualizing intercultural competence. In D. K. Deadorff (Ed.), The SAGE handbook of intercultural competence (pp.252). Thousand Oaks, CA: SAGE.

Tanaka, K. (2007). Japanese students' contact with English outside the classroom during study abroad. New Zealand Studies in Applied Linguistics, 13(1), 36-54.

Vande Berg, M., Connor-Linton, J., \& Paige, R. M. (2009). The Georgetown Consortium Project: Interventions for study abroad learning. The Interdisciplinary Journal of Study Abroad, 18, 1-75.

Walsh, R., \& Walsh, M. (2018). In their own words: American students' perspectives on study abroad experiences. The Humanistic Psychologist, 46(2), 129-146.

Williams, T. R. (2005). Exploring the impact of study abroad on students' intercultural communication skills: Adaptability and sensitivity. Journal of Studies in International Education, 9(4), 356-371.

Willy, A. (2017). Validation analysis of the Intercultural Development Inventory (IDI). Las Vegas, NV: ACE Ventures.

Wooldridge, D. G., Peet, S., \& Meyer, L. L. (2018). Transforming professionals through short-term study-abroad experiences. Delta Kappa Gamma Bulletin, 84(4), 31-36.

Yarosha, M., Lukic, D., \& Santibáñez-Gruber, R. (2018). Intercultural competence for students in international joint master programmes. International Journal of Intercultural Relations, 66, 52-72.

SHINGO HANADA, PhD, is an Associate Professor in the Faculty of Global and Regional Studies at Toyo University in Japan. His major research interests lie in the area of empirical studies on the impact of international education programs. Email: hanada@toyo.jp 